\title{
Role of V-ATPases in solid tumors: Importance of the subunit $\mathrm{C}$ (Review)
}

\author{
MARIO PÉREZ-SAYÁNS, ABEL GARCÍA-GARCÍA, \\ MARÍA DOLORES REBOIRAS-LÓPEZ and PILAR GÁNDARA-VILA
}

Facultad de Odontología, Entrerríos s/n, Santiago de Compostela, C.P. 15782, Spain

Received December 5, 2008; Accepted January 15, 2009

DOI: 10.3892/ijo_00000280

\begin{abstract}
Acidity is one of the main characteristics of OSCC (oral squamous cell carcinoma) as a solid tumor. The VATPase is the primary regulator of the tumor microenvironment, by means of proton extrusion to the extracellular medium. The decrease in extracellular $\mathrm{pH}$ confers the cells a resistant, highly invasive and metastatic phenotype. However, the acid medium confers an optimum $\mathrm{pH}$ to the degradative enzymes (such as proteases and MMPs) for their proper functioning. The $\mathrm{C}$ subunit (ATP6V1C) of V1 intra-membrane domain of the V-ATPase, is primarily responsible for its enzymatic function, through the control of a reversible dissociation of V0 and V1 domains. In this review, we describe the importance of V-ATPases in the control of tumor microenvironment, the potential strategies as protein targeting to improve the effectiveness of drug treatment and the role of the $\mathrm{C}$ subunit as the primarily responsible of the enzymatic control. The inhibition of the V-ATPase activity through PPIs (proton inhibitors) seems to reduce the destructive and metastatic capacity in tumors, such as hepatocellular carcinoma. Nevertheless, none of these inhibitors was proven to be useful in OSCC; therefore, it is highly important to carry out further studies in order to develop specific inhibitors of the $\mathrm{C}$ subunit, to control the devastating effects of OSCC.
\end{abstract}

\section{Contents}

1. Introduction

2. Role of V-ATPases in oral cancer

3. V-ATPases as protein targeting

4. Importance of $\mathrm{C}$ subunit

5. Conclusions

Correspondence to: Dr Mario Pérez-Sayáns, Facultad de Odontología, Entrerríos s/n, Santiago de Compostela, C.P. 15782, Spain

E-mail: perezsayans@gmail.com

Key words: oral squamous cell carcinoma, V-ATPase

\section{Introduction}

The main characteristics of the solid tumors (such as oral cancer) are the acidity and hypoxia, phenomena that result from the progression of metastatic cancer (1), the sensitivity to chemotherapeutic agents (2) and proliferation (3). In fact, a mechanism of resistance to cytotoxic drugs is the alteration of the $\mathrm{pH}$ gradient between the extracellular environment and cell cytoplasm (4).

The cytosolic $\mathrm{pH}$ seems to be strictly regulated by four mechanisms: the family of sodium-proton exchangers (NHE), the family of bicarbonate transporters (BCT), the family of monocarboxylate transporters (MCT) and the proton pumps (ATPase) $(5,6)$ (Fig. 1). The lactate production has been commonly seen as the first acidification mechanism of the microenvironment (7). The lactate accumulation results in the activation of the aerobic glycolytic metabolism (8) which increases the amount of cellular lactate that is transported outside the cell through the $\mathrm{H}^{+} /$lactate co-transporter (MCT) (9). The increase in aerobic glycolysis $(8,10)$ provides to the tumor a metabolic environment characterized by low levels of serum, hypoxia and an acid extracellular $\mathrm{pH}$. This microenvironment increases the invasive ability of the tumor and the expression of growth and angiogenic factors/receivers (11). All this is correlated to an increment of the intracellular $\mathrm{pH}$, an aggravation of the initial development of the interstitial acid microenvironment and a reversed transmembrane $\mathrm{pH}$ gradient $(11,12)$. This increase in the intracellular $\mathrm{pH}$ is concomitant with an increment of DNA synthesis $(8,13,14)$, cell cycle progression (15-17), serum and substrate-independent growth (8) and the in vivo growth of the tumor $(8,18)$ and all these phenomena trigger a pathological and disorganized increase in density and cell number. However, tumors are able to create an acidic environment even in conditions of reduced production of lactate, suggesting that the aerobic metabolism is not the major mechanism responsible for the development of an acidic microenvironment within solid tumors such as oral squamous cell carcinoma (OSCC) $(19,20)$. On the one hand, the same favourable conditions are maintained for the tumor cells, and on the other hand the selection of highly malignant cancer cells (which can survive in a hostile environment) is facilitated (21).

To survive in this microenvironment, tumor cells must have a regulatory system of cytosolic $\mathrm{pH}$ that assists cells in defending themselves against the dangerous $\mathrm{H}^{+}$ions. This 
could explain the fact that the V-ATPases, which normally reside in acidic organelles may be also located at the cell surface, regulating the $\mathrm{pH}$ and exacerbating the migratory ability of metastatic cells $(22,23)$.

\section{Role of V-ATPases in oral cancer}

The cell transformation and carcinogenesis processes are accompanied by metabolic disorders, increased production of protons, acidification of the extracellular environment and alkalization of the cytoplasm (24-26). Therefore, the development and maintenance of this gradient is due directly to the ability of tumor cells to secrete protons $\left(\mathrm{H}^{+}\right)$, acidify the extracellular environment $(11,12,26)$ and maintain an alkaline cytosolic $\mathrm{pH}$ (27). In addition, this ability is increased with the aggressiveness of the tumor $(28,29)$.

Immunohistochemical data show that the V-ATPase is located in the plasma membrane of breast $(23,24)$ and lung (30) cancer cells; this occurs prominently in the highly metastatic cells and with less intensity in the lowly metastatic cells $(23,24)$. Otero-Rey et al demonstrate the ATP6V1C1 overexpression in OSCC, one of the most significant subunit of the V-ATPases (31).

According to Martínez-Zaguilán et al (24) the V-ATPase expression in the plasma membrane is due to some kind of dysfunction of the normal constituents of the cell. These constituents include the cytoskeleton (32), leader sequences (33) or alterations in a chaperone (34). To Sennoune et al the changes in cytosolic $\mathrm{pH}$ have multiple phenotypic expression, but according to the authors, the alteration of a single protein (the V-ATPase in the plasma membrane) is responsible for the dysfunctions in protein and cellular pathways of cancer (27).

The acid component of the intratumoral metabolic microenvironment increases the metastatic potential by promoting the angiogenesis $(27,35)$, the anchorage-independent growth, the genetic instability (7) and the invasion, infiltration and penetration of cancer cells into the normal tissue (11).

Martínez-Zaguilán et al found that microvascular endothelial cells with the highest migratory capacity express $\mathrm{V}$-ATPases in the plasma membrane. The treatment of these cells with inhibitors of V-ATPases reduces the proton flux, via inhibition of V-ATPase in the plasma membrane (pmVATPases) and cell migration, suggesting that they are essential for the regulation of cytosolic $\mathrm{pH}$ and migration of endothelial cells (36).

The proton flux, via V-ATPase, evaluated by fluorescence spectroscopy in living cells, was greater in highly than in lowly metastatic cells. Curiously, the lowly metastatic cells use preferably $\mathrm{Na}^{+} / \mathrm{H}^{+}$and $\mathrm{HCO} 3$ - transporters, while highly metastatic cells use V-ATPases. Moreover, these latter cells are more invasive and migratory than the former. These data indicate that the pmV-ATPases are involved in the acquisition of a more metastatic phenotype (37).

The V-ATPases play an important role in the development of tumor metastasis, as previously said. Many tumor cells secrete lysosomal enzymes, involved in the degradation of the extracellular matrix, required for metastatic invasion. These enzymes have a low optimum $\mathrm{pH}$ and the V-ATPases are the only responsible for the microenvironment acidification $(24,38)$.

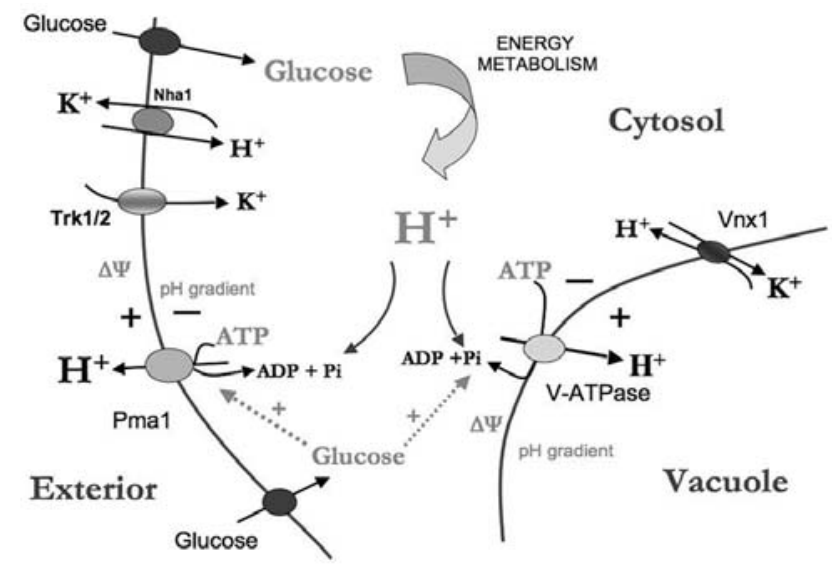

Figure 1. Role of the V-ATPase in the control of intra and extracellular $\mathrm{pH}$. Obtained from Martínez Muñoz and Kane (76).

The motility and invasive phenotype are the requirements that make the cell responsible for metastasis $(11,27)$.

The treatment with V-ATPase inhibitors (such as Bafilomycin A1 and Concanamycin A) inhibits the enzyme activity as well as the migratory ability of highly metastatic cells $(23,30)$. It has been shown that the greatest increase in the invasiveness of tumor cells is the result of two complementary mechanisms: breaking of the cell-matrix interactions that arise because of the acid secretion increment, the protease activity (such as Cathepsin B) and the increased cell motility $(11,23,30)$. The breast cancer cells, through V-ATPases, acidify the extracellular environment in order to facilitate the reabsorption of the extracellular matrix by means of proteases and metastasis (28).

Cell $\mathrm{pH}$ is crucial for several biological functions such as cell proliferation, invasion and metastasis, drug resistance and apoptosis. The hypoxic conditions are frequent phenomena during the OSCC development and they cause an intra- and extracellular acidosis. This cellular acidosis seems to be a trigger for apoptosis and allows the endonuclease activation that induces DNA fragmentation. The $\mathrm{pH}$ regulators should be over-regulated in the tumor cells in order to avoid intracellular acidification under the above-mentioned conditions (31).

As already mentioned, the tumor microenvironment is essential for the neoplastic progression and the reduction of extracellular $\mathrm{pH}$ is one of this microenvironment features. Since V-ATPase is the main proton pump regulator of the cell $\mathrm{pH}$, its involvement in the neoplastic progression should not surprise anyone.

\section{V-ATPases as protein targeting}

Growing scientific evidence suggests a key role of tumor acidic microenvironment in cancer development, in terms of progression and metastasis. Among all regulatory mechanisms of tumor microenvironment, the V-ATPases play a key role due to their inhibition possibility by means of RNA interference techniques and inhibitors of proton pump (39).

Early attempts to block the V-ATPases as a protein targeting date back to 1988, when Moriyama et al described the inhibition of V-ATPase activity, through blocking the 
Table I. Inhibitors of $\mathrm{pH}$ regulators.

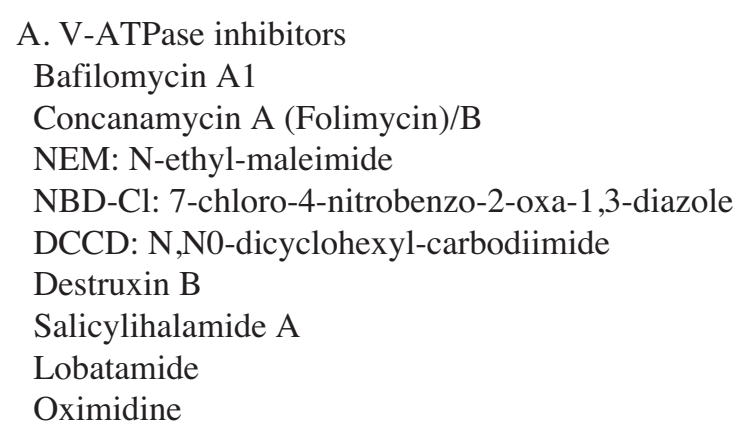

B. NHE inhibitors

Guanidine derivatives

(i) Benzoylguanidine

Cariporide, HOE642: 4-isopropyl-3-methylsulphonylbenzoyl-guanidine methanesulphonate

Hoe 694: 3-methylsulfonyl-4-piperidinobenzoyl, guanidine hydrochloride

FR183998: 5-(2,5-dichlorothiophen-3-yl)-3-[(2-dimethylaminoethyl)carbamoyl]benzoylguanidine dihydrochloride

FR168888: 5-hydroxymethyl-3-(pyrrol-1-yl) benzoylguanidine methanesulfonate

EMD 85131: 2-methyl-5-methylsulfonyl-1-(1-pyrrollyl)-benzoylguanidine

(ii) Carbonylguanidine

Zoniporide or CP-597,396: [1-(Quinolin-5-yl)-5-cyclopropyl-1H-pyrazole-4-carbonyl]guanidine hydrochloride monohydrate TY-12533: 6,7,8,9-tetrahydro-2-methyl-5H-cyclohepta[b]pyridine-3-carbonylguanidine maleate

CAS 181048-29-3, MS-31-050: 2-(2-methylphenyl)-5,7-dimethoxy-4-quinolyl carbonylguanidine dihydrochloride

CAS 181048-36-2, MS-31-038: 2-phenyl-8-(2-methoxyethoxy)-4-quinolyl carbonylguanidine bismethanesulfonate KB-R9032: N-(4-isopropyl-2,2-dimethyl-3-oxo-3,4-dihydro-2H-benzo[1,4]oxazine-6-car bonyl)guanidine (4b) methanesulfonate salt

(iii) Others

T-162559: (5E,7S)-[7-(5-fluoro-2-methylphenyl)-4-methyl-7,8-dihydro-5(6H)-quinolinylideneamino] guanidine dimethanesulphonate

Amiloride derivatives

DMA: 50-(N,N-dimethyl)-amiloride

HMA: 5-(N,N-hexamethylene) amiloride

MIA: 5-(N-ethyl-N-isopropyl)-amiloride

C. Bicarbonate transporter inhibitor

Triflocin: 4-(a,a,a-trifluoro-m-toluidino)-nicotinic acid

DIDS: 4,40-diisothiocyanato-stilbene-2,20-disulfonic acid

SITS: 4-acetamido-40;isothiocyanostilbene-2,20-disulfonic acid

S3705

D. MCT inhibitors

DIDS: 4,40-diisothiocyanato-stilbene-2,20-disulfonic acid

a-cyano-4-hydroxycinnamate (a-CHC)

p-Chloromercuribenzenesulphonate

Diethyl pyrocarbonate

Quercetin

assembly and reducing $\mathrm{H}^{+}$secretory activity, using fusidic acid and suramin (40).

In 2001, Boyd et al described a small group of molecules that share a common core of benzyl-lactate-enamide in their structure. These molecules are proton pump inhibitors (PPI) (Table I). The most representative are the following: salicylamide A, lobatamides A-F, oxymidines $I$ and II, bafilomycins and canamycins. Of these, the authors found that the latter two are the most potent V-ATPase inhibitors and even that there is no distinction between mammalian and non-mammalian V-ATPases. This inhibition causes a reduction in the development of tumor cells and cell lines with oncogenes (41) through programmed cell death (apoptosis) (42). The PPI effect is mediated by a very early production of reactive oxygen species (ROS) that preceded alkalinization of lysosomal $\mathrm{pH}$, lysosomal membrane permeabilization, and cytosol acidification, suggesting an early destabilization of the acidic vesicular compartment. Lysosomal alterations were followed by mitochondrial membrane depolarization, release of cytochrome c, chromatin condensation, and caspase 


\section{V-ATPase}

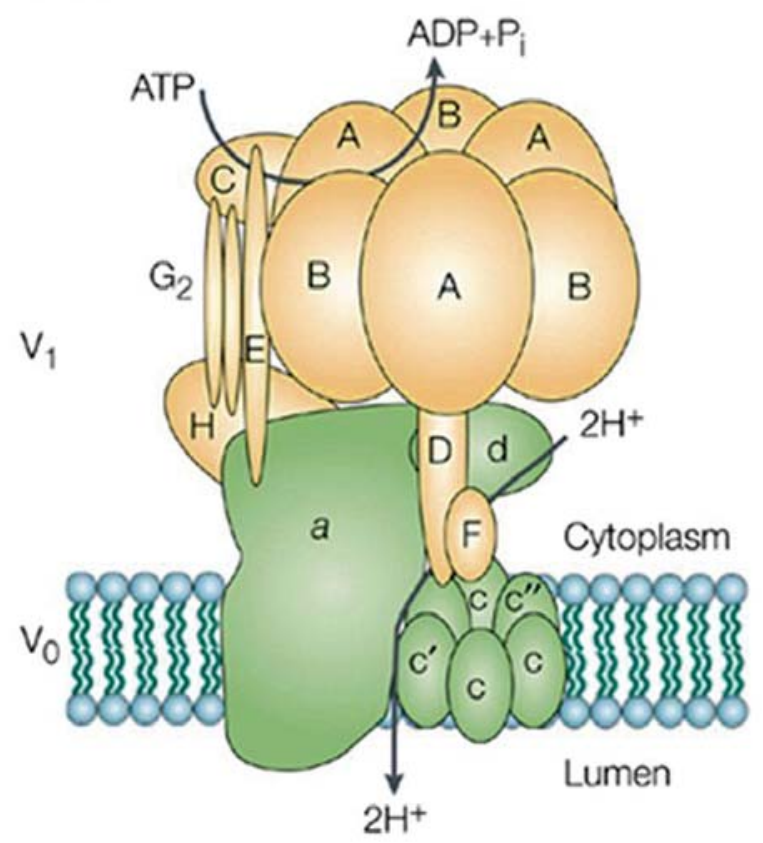

Figure 2. The cytosolic domain V1 (shown in yellow), is composed of three subunits A and three subunits B, two subunits $\mathrm{G}$ and one subunit of types C, $\mathrm{D}, \mathrm{E}, \mathrm{F}$ and $\mathrm{H}$. The transmembrane domain Vo (shown in green) is composed of five different subunits: a, c, c', c" and d. ATP hydrolysis by the peripheral V1 domain drives proton transport through the integral V0 domain from the cytoplasm to the lumen. Modified from Nishi and Forgac (37).

activation (43). It seems that the ROS have a clear effect on oral carcinogenesis (44).

Regarding B-cell lymphomas, the proapoptotic activity of PPI is clearly related to the inhibition of tumor growth (43).

Yoshimoto and Imoto show new roles of V-ATPase inhibitors in tumor cells that overexpress EGFR (epidermal growth factor receptor). The authors find that the V-ATPase inhibitors induce apoptosis in EGFR-stimulated A431 cells (human epidermal carcinoma) with the same dose range that inhibits the V-ATPase activity. However, when cells are not stimulated by EGFR, the inhibitors do not induce apoptosis, while they put a brake on cell growth, independently of the cell cycle (45).

The ATP6L or the $\mathrm{C}$ subunit of $\mathrm{V0}$ domain has been determined in recent studies as a possible target in the suppression of metastasis and tumor growth via V-ATPase inhibition, aimed at altering the acid microenvironment of the extracellular matrix, which is necessary for the activity of many MMPs (metalloproteinases) and proteases $(23,27,46,47)$.

Saroussi and Nelson (23) and Ohta et al (48) note that V-ATPase C subunit emerges as overexpressed in pancreatic invasive tumors when compared to benign or non-invasive tumors, suggesting that the V-ATPase may have a key role in tumor progression.

However, Otero-Rey et al find that ATP6V0C is not overexpressed in OSCC in a statistically significant way, so that blocking this gene does not seem to be very useful in this type of tumors (31).

Lu et al demonstrate the ability to slow tumor growth and to suppress distant metastasis in human hepatocellular carcinoma, by the decrease of proton extrusion and the activity of the gelatinase, via inhibition of $\mathrm{C}$ subunit gene (ATP6L) by using RNA interference techniques (47).

It has been shown that the E5 oncoprotein of the bovine papillomavirus binds to the $\mathrm{C}$ subunit of V-ATPase V0 domain (49,50), triggering a Golgi alkalization that correlates with cell transformation induced by this protein (51); therefore, blocking the V-ATPase via inhibition of $\mathrm{C}$ subunit could suppress the carcinogenic effects of HPV.

It seems that Concanamycin $\mathrm{A}$ binds to the $\mathrm{C}$ subunit of the V0 (52) domain as well as the Bafilomycin (53). According to Bowman (75) the mutations in the genomic sequence of the $\mathrm{C}$ subunit (four mutations have been found: T32I, F136L, Y143H and $\mathrm{Y} 143 \mathrm{~N}$ ) give the cell the ability to resist Bafilomycin A1.

There are other new specific inhibitors of the V-ATPases, which are already synthesized in the laboratory as the analogues of archazolid A and B (54). The use of the novel NiK12192 V-ATPase inhibitor increases the anti-tumor activity of other chemotherapeutic drugs $(23,55)$. Another study shows the efficacy of FR202126 (a specific V-ATPase inhibitor of osteoclasts) in decreasing the osteolysis in the lung cancer metastasis (56).

However, it seems that none of these inhibitors has been proven useful in the OSCC, so that it is of high importance to carry out further research in order to determine the actual implication of V-ATPases in cancer development and implementation of other inhibitors in the subunits responsible for enzyme assembly (23).

\section{Importance of $\mathrm{C}$ subunit}

V-ATPase is composed of a cytosolic V1 domain and a transmembrane V0 domain. The V1 domain consists of three A and three B subunits, two G subunits as well as a C, D, E, F and $\mathrm{H}$ subunit. $\mathrm{C}$ subunit is analogue but not homologous to the subunit $\gamma$ of F-ATPases (Fig. 2). Two alternative transcript variants, ATP6V1C1 and ATP6V1C2, a and b, that encode different isoforms, have been found for this gene. Regarding the ATP6V1C1, it is always expressed in all tissues, while ATP6V1C2a, b are found in lungs, kidneys and epididymis with an actin-binding function (57).

The $\mathrm{C}$ subunit is the $40-\mathrm{kDa}$ protein, located in the V1 domain of the V-ATPase. The novel imaging techniques such as SAXS (small angle X-ray scattering) allow describing the structure and morphology of the $\mathrm{C}$ subunit and its involvement in the regulation of V-ATPases $(58,59)$.

By means of immune electronic microscopy, we can determine the spatial location and distribution of the various subunits, in this case of the $\mathrm{C}$ subunit $(60,61)$. The model proposed by Zhang et al coincides with the one proposed by Drory et al which stipulates that the crystal structure of the $\mathrm{C}$ subunit consists of two globular domains connected by a flexible connection (62) (Fig. 3).

Inoue and Forgac, besides establishing the crystal structure of the $\mathrm{C}$ subunit and its importance in the reversible dissociation as a mechanism for monitoring the V-ATPase activity, describe the connection of the latter with the $G$ and $E$ subunit of the V1 domain and the A subunit of the V0 domain, establishing the importance of the $\mathrm{C}$ subunit as the highest responsible for the enzyme control $(63,64)$. 

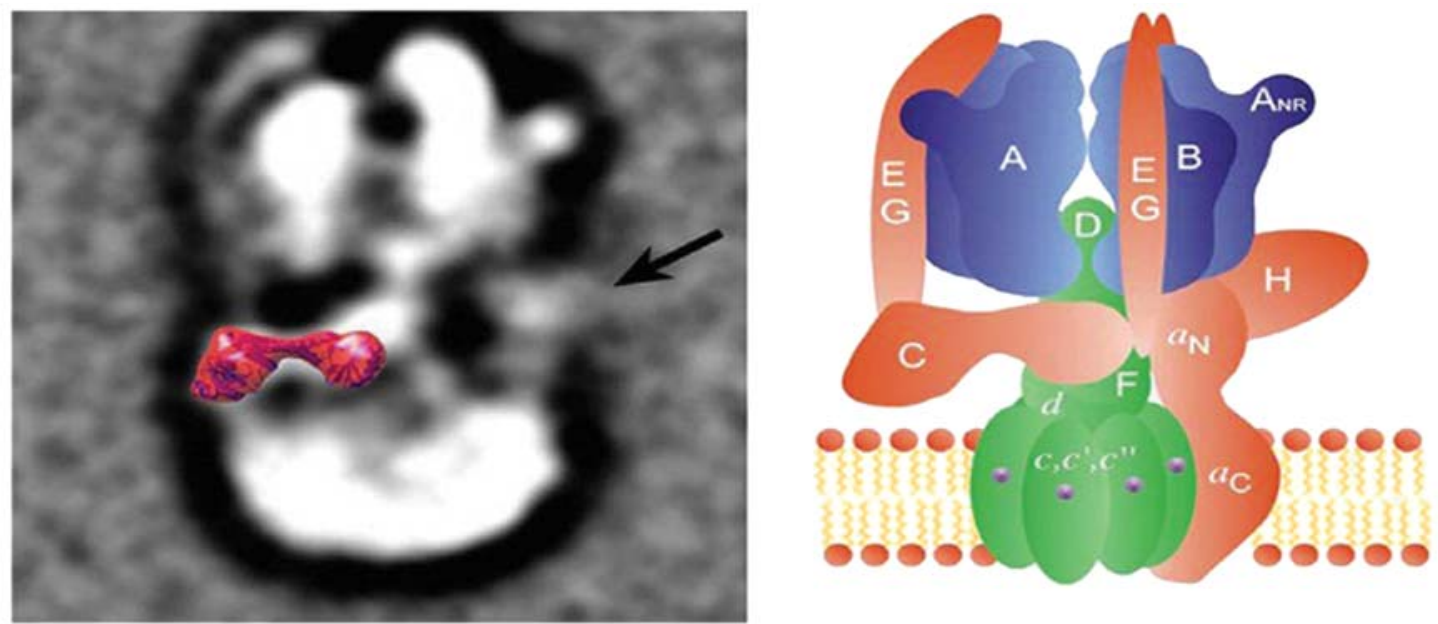

Figure 3. Image of the crystallographic structure of the $\mathrm{C}$ subunit and schematic work model. (A) The surface representation of the crystal structure of yeast subunit $\mathrm{C}$ is superimposed to match the observed density in the yeast V-ATPase projection. (B) Schematic working model of the subunit arrangement in the yeast V-ATPase. Modified from Zhang et al (60).
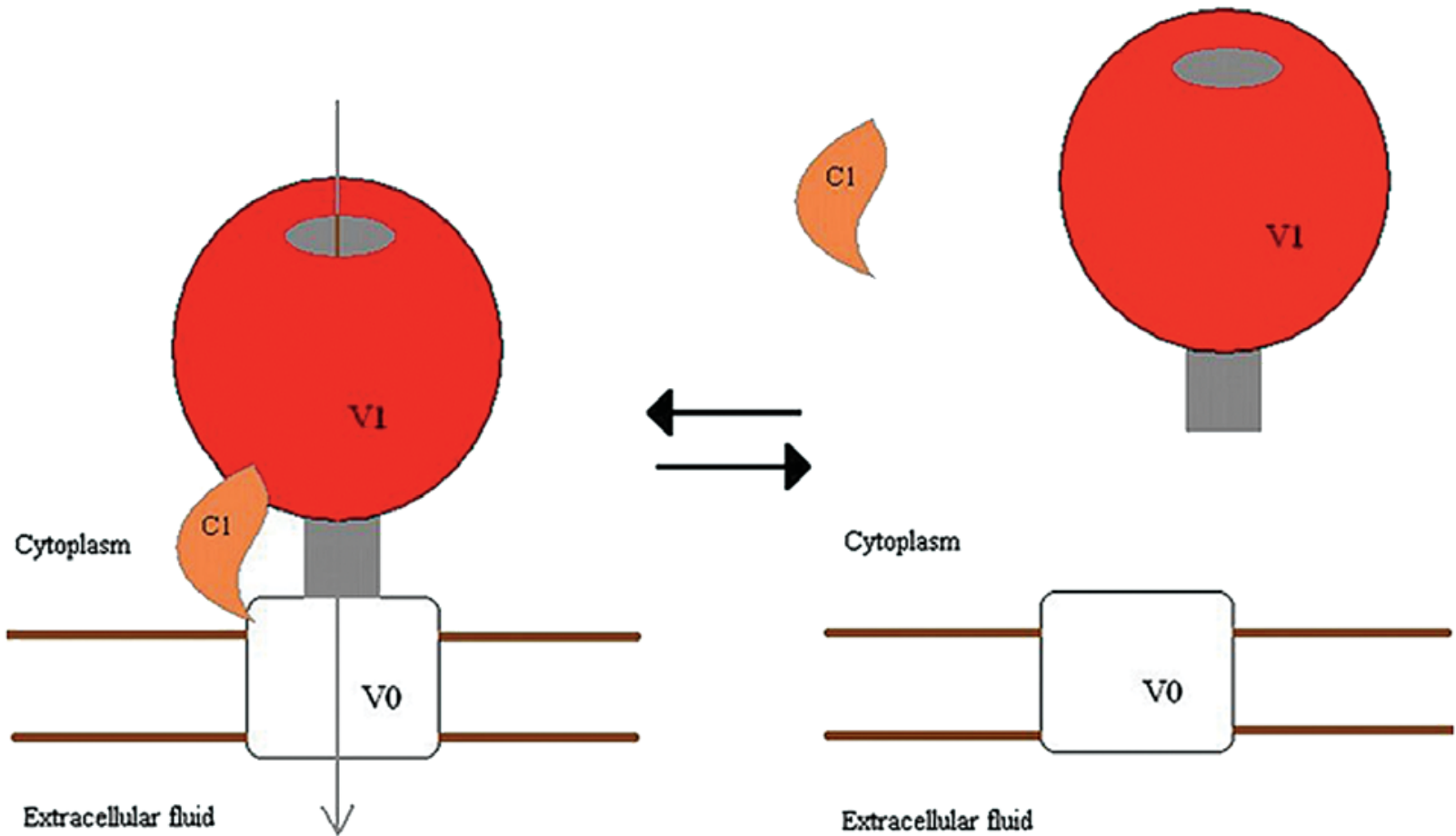

Extracellular fluid

Figure 4. Structural model of the vacuolar $\mathrm{H}^{+}$-ATPase, comprising a membrane component (V0) and a catalytic cytosolic component (V1). Dissociation of the VATPase into the V1 and V0 components is regulated by the C1 subunit. Obtained from Otero-Rey (31).

In an experimental model, Peng et al show that the $\mathrm{C}$ subunit is crucial to proton secretion function of the VATPases, since the ATP hydrolysis is blocked without it (65).

To many authors, the most important function of the subunit $\mathrm{C}$ is the control of reversible dissociation. According to Grüber et al subunit $\mathrm{C}$ is intimately involved in the reversible dissociation of the $\mathrm{V} 0$ and $\mathrm{V} 1$ domains. The nucleotide occupation of this latter and the conformational change in its structure allow such a dissociation $(66,67)$.

At first, Puopolo et al assert that during the formation of the complex V1V0, subunit $\mathrm{C}$ speeds up the process but it is not essential (68), although these results are discussed in other studies of the same period of time, that defend the hypothesis of the $\mathrm{C}$ subunit as the only regulatory of the dissociative mechanism (69). This theory is supported by Drory et al who state that the $\mathrm{C}$ subunit is the only responsible for the in vivo dissociation of the V-ATPase (62). According to Voss et al the $\mathrm{C}$ subunit is responsible for producing the dissociation of the $\mathrm{V}$-ATPase in the cytosolic V1 complex and in the membranous V0 complex through interaction with A-kinase protein. It seems that the $\mathrm{C}$ subunit serves as a substrate for the A-kinase protein and its phosphorylation may be the main mechanism of forming the active V1V0 holoenzyme (70).

Another mechanism of reversible dissociation regulated by the $\mathrm{C}$ subunit is the separation of V1V0 holoenzyme in $\mathrm{V} 1$ and V0 subcomplex, which is carried out through binding this 
holoenzyme to the F-actin next to the basement membrane of epithelial cells. It seems that the $\mathrm{C}$ subunit acts as an anchor protein, allowing the connection between the V-ATPase and the actinic cytoskeleton (32).

In a study of our research group, we have demonstrated the overexpression of the ATP6V1C1 gene in OSCC biopsies. It seems that the $\mathrm{C} 1$ subunit of $\mathrm{V}$-ATPases is responsible for allowing the assembly of membranous V0 component and cytosolic catalytic component (31) (Fig. 4). The RAVE complex (V-ATPase regulator and endosomal membranes) is essential for stable assembly of the $\mathrm{C}$ subunit of V-ATPase $(64,71)$.

Smardon and Kane found in vitro that without the C subunit, the assembly of the two domains occurred, but the V1V0 complex was highly unstable and the activity of the VATPase extremely low, suggesting the exclusivity of the C subunit in regulating the complex V1V0 assembly. In the same way, the $\mathrm{C}$ subunit is incapable of getting assembled to the V-ATPase without RAVE and therefore, the enzyme activity is lost (71). These data are supported by the study made by Keenan and Kane who find a $48 \%$ higher decrease in catalytic activity, without affecting the enzyme assembly in experimental models with different mutations in the gene of the C subunit (72).

Previous studies suggest that the cells that express high levels of $\mathrm{C}$ subunit have an increased resistance to chemotherapeutic agents, so they may be a possible target in anticancer therapy (73).

Murakami et al found an overexpression of the ATP6C gene or $\mathrm{C}$ subunit in the cisplatin-resistant tumors, a logical fact given the V-ATPase increased number and activity in cases of chemoresistance and the importance of this subunit in the regulation of the pump (74).

\section{Conclusions}

Cell $\mathrm{pH}$ is crucial for several biological functions such as cell proliferation, invasion and metastasis, drug resistance and apoptosis. The hypoxic conditions are frequent phenomena during the development of oral cancer and trigger an intraand extracellular acidosis. This cellular acidosis seems to be mainly controlled by the V-ATPases, which are clearly involved in cell transformation, carcinogenesis and metastasis.

The inhibition of V-ATPase with PPIS allows the anticancer drugs to enter and act within the tumor cells, causing apoptotic mechanisms that lead to the inhibition of tumor growth.

The involvement of the $\mathrm{C}$ subunit of the V1 domain in the enzymatic function of the V-ATPases, highlights the need for further research of specific inhibitors of the above-mentioned subunit in order to control the disastrous consequences of cancer.

\section{References}

1. Martinez-Zaguilan R, Seftor EA, Seftor RE, Chu YW, Gillies RJ and Hendrix MJ: Acidic $\mathrm{pH}$ enhances the invasive behavior of human melanoma cells. Clin Exp Metastasis 14: 176-186, 1996.

2. Raghunand N, Mahoney B, van Sluis R, Baggett B and Gillies RJ: Acute metabolic alkalosis enhances response of $\mathrm{C} 3 \mathrm{H}$ mouse mammary tumors to the weak base mitoxantrone. Neoplasia 3: 227-235, 2001
3. Morita T, Nagaki T, Fukuda I and Okumura K: Clastogenicity of low $\mathrm{pH}$ to various cultured mammalian cells. Mutat Res 268: 297-305, 1992.

4. De Milito A and Fais S: Proton pump inhibitors may reduce tumour resistance. Expert Opin Pharmacother 6: 1049-1054, 2005.

5. Izumi H, Torigoe T, Ishiguchi H, Uramoto H, Yoshida Y, Tanabe $\mathrm{M}$, et al: Cellular $\mathrm{pH}$ regulators: potentially promising molecular targets for cancer chemotherapy. Cancer Treat Rev 29: 541-549, 2003.

6. Torigoe $\mathrm{T}$, Izumi $\mathrm{H}$, Ise $\mathrm{T}$, Murakami $\mathrm{T}$, Uramoto $\mathrm{H}$ and Ishiguchi $\mathrm{H}$ : Vacuolar $\mathrm{H}(+)$-ATPase: functional mechanisms and potential as a target for cancer chemotherapy. Anticancer Drugs 13: 237-243, 2002.

7. Gillies RJ, Raghunand N, Karczmar GS and Bhujwalla ZM: MRI of the tumor microenvironment. J Magn Reson Imaging 16: 430-450, 2002.

8. Reshkin SJ, Bellizzi A, Caldeira S, Albarani V, Malanchi I and Poignee $\mathrm{M}$ : $\mathrm{Na}^{+} / \mathrm{H}^{+}$exchanger-dependent intracellular alkalinization is an early event in malignant transformation and plays an essential role in the development of subsequent transformation-associated phenotypes. FASEB J 14: 2185-2197, 2000.

9. Juel C: Lactate-proton cotransport in skeletal muscle. Physiol Rev 77: 321-358, 1997.

10. Raghunand $\mathrm{N}$ and Gillies $\mathrm{RJ}: \mathrm{pH}$ and drug resistance in tumors. Drug Resist Updat 3: 39-47, 2000.

11. Cardone RA, Casavola V and Reshkin SJ: The role of disturbed $\mathrm{pH}$ dynamics and the $\mathrm{Na}^{+} / \mathrm{H}^{+}$exchanger in metastasis. Nat Rev Cancer 5: 786-795, 2005.

12. Sennoune SR, Luo D and Martinez-Zaguilan R: Plasmalemmal vacuolar-type $\mathrm{H}^{+}$-ATPase in cancer biology. Cell Biochem Biophys 40: 185-206, 2004.

13. Hagag N, Lacal JC, Graber M, Aaronson S and Viola MV: Microinjection of ras p21 induces a rapid rise in intracellular $\mathrm{pH}$. Mol Cell Biol 7: 1984-1988, 1987.

14. Ober SS and Pardee AB: Intracellular $\mathrm{pH}$ is increased after transformation of Chinese hamster embryo fibroblasts. Proc Natl Acad Sci USA 84: 2766-2770, 1987.

15. Reshkin SJ, Bellizzi A, Albarani V, Guerra L, Tommasino M and Paradiso A: Phosphoinositide 3-kinase is involved in the tumorspecific activation of human breast cancer cell $\mathrm{Na}(+) / \mathrm{H}(+)$ exchange, motility, and invasion induced by serum deprivation. J Biol Chem 275: 5361-5369, 2000.

16. Siczkowski M, Davies JE and Ng LL: Activity and density of the $\mathrm{Na}^{+} / \mathrm{H}^{+}$antiporter in normal and transformed human lymphocytes and fibroblasts. Am J Physiol 267: C745-C752, 1994.

17. Doppler W, Jaggi R and Groner B: Induction of v-mos and activated Ha-ras oncogene expression in quiescent NIH 3 T3 cells causes intracellular alkalinisation and cell-cycle progression. Gene 54: 147-153, 1987.

18. Pouyssegur J, Franchi A and Pages G: pHi, aerobic glycolysis and vascular endothelial growth factor in tumour growth. Novartis Found Symp 240: 186-196, 2001.

19. Newell K, Franchi A, Pouyssegur J and Tannock I: Studies with glycolysis-deficient cells suggest that production of lactic acid is not the only cause of tumor acidity. Proc Natl Acad Sci USA 90: 1127-1131, 1993.

20. Yamagata M, Hasuda K, Stamato T and Tannock IF: The contribution of lactic acid to acidification of tumours: studies of variant cells lacking lactate dehydrogenase. Br J Cancer 77: 1726-1731, 1998.

21. De Milito A and Fais S: Tumor acidity, chemoresistance and proton pump inhibitors. Future Oncol 1: 779-786, 2005.

22. Nelson $\mathrm{N}$ and Harvey WR: Vacuolar and plasma membrane proton-qdenosinetriphosphatases. Physiol Rev 79: 361-385, 1999.

23. Saroussi S and Nelson N: Vacuolar H(+)-ATPase-an enzyme for all seasons Pflugers Arch 457: 581-587, 2009.

24. Martinez-Zaguilan R, Lynch RM, Martinez GM and Gillies RJ: Vacuolar-type $\mathrm{H}(+)$-ATPases are functionally expressed in plasma membranes of human tumor cells. Am J Physiol Cell Physiol 265: C1015-C1029, 1993.

25. McLean LA, Roscoe J, Jorgensen NK, Gorin FA and Cala PM: Malignant gliomas display altered $\mathrm{pH}$ regulation by $\mathrm{NHE} 1$ compared with nontransformed astrocytes. Am J Physiol Cell Physiol 278: C676-C688, 2000.

26. Perona $\mathrm{R}$ and Serrano R: Increased $\mathrm{pH}$ and tumorigenicity of fibroblasts expressing a yeast proton pump. Nature 334: 438-440, 1988. 
27. Sennoune SR and Martinez-Zaguilan R: Plasmalemmal vacuolar $\mathrm{H}^{+}$-ATPases in angiogenesis, diabetes and cancer. J Bioenerg Biomembr 39: 427-433, 2007.

28. Montcourrier P, Silver I, Farnoud R, Bird I and Rochefort H: Breast cancer cells have a high capacity to acidify extracellular milieu by a dual mechanism. Clin Exp Metastasis 15: 382-392, 1997.

29. Parkins CS, Stratford MR, Dennis MF, Stubbs M and Chaplin DJ: The relationship between extracellular lactate and tumour $\mathrm{pH}$ in a murine tumour model of ischaemia-reperfusion. Br J Cancer 75: 319-323, 1997

30. Sennoune SR, Bakunts K, Martinez GM, Chua-Tuan JL, Kebir Y, Attaya MN, et al: Vacuolar $\mathrm{H}^{+}-\mathrm{ATPase}$ in human breast cancer cells with distinct metastatic potential: distribution and functional activity. Am J Physiol Cell Physiol 286: C1443-C1452, 2004.

31. Otero-Rey EM, Somoza-Martin M, Barros-Angueira F and Garcia-Garcia A: Intracellular $\mathrm{pH}$ regulation in oral squamous cell carcinoma is mediated by increased V-ATPase activity via over-expression of the ATP6V1C1 gene. Oral Oncol 44: 193-199, 2008

32. Vitavska O, Wieczorek $\mathrm{H}$ and Merzendorfer $\mathrm{H}$ : A novel role for subunit $\mathrm{C}$ in mediating binding of the $\mathrm{H}^{+}-\mathrm{V}-\mathrm{ATPase}$ to the actin cytoskeleton. J Biol Chem 278: 18499-18505, 2003.

33. Izumi H, Ise $\mathrm{T}$, Murakami $\mathrm{T}$, Torigoe $\mathrm{T}$, Ishiguchi $\mathrm{H}$ and Uramoto H: Structural and functional characterization of two human V-ATPase subunit gene promoters. Biochimica et Biophysica Acta (BBA) - Gene Structure and Expression 1628: 97-104, 2003.

34. Orive G, Reshkin SJ, Harguindey S and Pedraz JL: Hydrogen ion dynamics and the $\mathrm{Na}^{+} / \mathrm{H}^{+}$exchanger in cancer angiogenesis and antiangiogenesis. Br J Cancer 89: 1395-1399, 2003.

35. Rojas JD, Sennoune SR, Maiti D, Bakunts K, Reuveni M, Sanka SC, et al: Vacuolar-type $\mathrm{H}^{+}$-ATPases at the plasma membrane regulate $\mathrm{pH}$ and cell migration in microvascular endothelial cells. Am J Physiol Heart Circ Physiol 291: H1147-H1157, 2006.

36. Martínez-Zaguilán R, Raghunand N, Lynch RM, Bellamy W, Martinez GM and Rojas B: pH and drug resistance. I. functional expression of plasmalemmal V-type $\mathrm{H}^{+}$-ATPase in drug-resistant human breast carcinoma cell lines. Biochem Pharmacol 57: 1037-1046, 1999.

37. Nishi T and Forgac M: The vacuolar (H+)-ATPases-nature's most versatile proton pumps. Nat Rev Mol Cell Biol 3: 94-103, 2002 .

38. Nelson N, Perzov N, Cohen A, Hagai K, Padler V and Nelson H: The cellular biology of proton-motive force generation by $\mathrm{V}$ ATPases. J Exp Biol 203: 89-95, 2000.

39. Fais S, De Milito A, You H and Qin W: Targeting vacuolar $\mathrm{H}^{+}$-ATPases as a new strategy against cancer. Cancer Res 67 : 10627-10630, 2007

40. Moriyama $\mathrm{Y}$ and Nelson $\mathrm{N}$ : Inhibition of vacuolar $\mathrm{H}^{+}-\mathrm{ATPases}$ by fusidic acid and suramin. FEBS Lett 234: 383-386, 1988

41. Boyd MR, Farina C, Belfiore P, Gagliardi S, Kim JW and Hayakawa Y: Discovery of a novel antitumor benzolactone enamide class that selectively inhibits mammalian vacuolar-type (H+)-ATPases. J Pharmacol Exp Ther 297: 114-120, 2001.

42. Nishihara T, Akifusa S, Koseki T, Kato S, Muro M and Hanada N: Specific inhibitors of vacuolar type H(+)-ATPases induce apoptotic cell death. Biochem Biophys Res Commun 212 255-262, 1995

43. De Milito A, Iessi E, Logozzi M, Lozupone F, Spada M and Marino ML: Proton pump inhibitors induce apoptosis of human B-cell tumors through a caspase-independent mechanism involving reactive oxygen species. Cancer Res 67: 5408-5417, 2007.

44. Bahar G, Feinmesser R, Shpitzer T, Popovtzer A and Nagler RM: Salivary analysis in oral cancer patients: DNA and protein oxidation, reactive nitrogen species, and antioxidant profile. Cancer 109: 54-59, 2007.

45. Yoshimoto $\mathrm{Y}$ and Imoto $\mathrm{M}$ : Induction of EGF-dependent apoptosis by vacuolar-type $\mathrm{H}(+)$-ATPase inhibitors in A431 cells overexpressing the EGF receptor. Exp Cell Res 279: 118-127, 2002.

46. Germanov E, Berman JN and Guernsey DL: Current and future approaches for the therapeutic targeting of metastasis (review). Int J Mol Med 18: 1025-1036, 2006.

47. Lu X, Qin W, Li J, Tan N, Pan D, Zhang H, et al: The growth and metastasis of human hepatocellular carcinoma xenografts are inhibited by small interfering RNA targeting to the subunit ATP6L of proton pump. Cancer Res 65: 6843-6849, 2005
48. Ohta T, Numata M, Yagishita H, Futagami F, Tsukioka Y and Kitagawa $\mathrm{H}$ : Expression of $16 \mathrm{kDa}$ proteolipid of vacuolar-type $\mathrm{H}(+)$-ATPase in human pancreatic cancer. Br J Cancer 73: $1511-1517,1996$

49. Goldstein DJ, Finbow ME, Andresson T, McLean P, Smith K and Bubb V: Bovine papillomavirus E5 oncoprotein binds to the $16 \mathrm{~K}$ component of vacuolar H(+)-ATPases. Nature 352: 347-349, 1991.

50. Andresson T, Sparkowski J, Goldstein DJ and Schlegel R: Vacuolar H(+)-ATPase mutants transform cells and define a binding site for the papillomavirus E5 oncoprotein. J Biol Chem 270: 6830-6837, 1995.

51. Schapiro F, Sparkowski J, Adduci A, Suprynowicz F, Schlegel R and Grinstein S: Golgi alkalinization by the papillomavirus E5 oncoprotein. J Cell Biol 148: 305-315, 2000.

52. Huss M, Ingenhorst G, Konig S, Gassel M, Drose S, Zeeck A, et al: Concanamycin A, the specific inhibitor of V-ATPases, binds to the V(o) subunit c. J Biol Chem 277: 40544-40548, 2002.

53. Fernandes F, Loura LM, Fedorov A, Dixon N, Kee TP and Prieto M: Binding assays of inhibitors towards selected V-ATPase domains. Biochim Biophys Acta 1758: 1777-1786, 2006.

54. Menche D, Hassfeld J, Sasse F, Huss M and Wieczorek H: Design, synthesis, and biological evaluation of novel analogues of archazolid: a highly potent simplified V-ATPase inhibitor. Bioorg Med Chem Lett 17: 1732-1735, 2007.

55. Petrangolini G, Supino R, Pratesi G, Bo LD, Tortoreto M and Croce AC: Effect of a novel vacuolar- $\mathrm{H}^{+}-\mathrm{ATPase}$ inhibitor on cell and tumor response to camptothecins. J Pharmacol Exp Ther 318: 939-946, 2006.

56. Niikura K: Effect of a V-ATPase inhibitor, FR202126, in syngeneic mouse model of experimental bone metastasis. Cancer Chemother Pharmacol 60: 555-562, 2007.

57. Smith AN, Borthwick KJ and Karet FE: Molecular cloning and characterization of novel tissue-specific isoforms of the human vacuolar $\mathrm{H}(+)$-ATPase $\mathrm{C}, \mathrm{G}$ and d subunits, and their evaluation in autosomal recessive distal renal tubular acidosis. Gene 297: 169-177, 2002.

58. Svergun DI, Konrad S, Huss M, Koch MH, Wieczorek H and Altendorf K: Quaternary structure of V1 and F1 ATPase: significance of structural homologies and diversities. Biochemistry 37: 17659-17663, 1998.

59. Armbruster A, Svergun DI, Coskun U, Juliano S, Bailer SM and Gruber G: Structural analysis of the stalk subunit Vma5p of the yeast V-ATPase in solution. FEBS Lett 570: 119-125, 2004.

60. Zhang Z, Inoue $T$, Forgac $M$ and Wilkens $S$ : Localization of subunit $\mathrm{C}$ (Vma5p) in the yeast vacuolar ATPase by immuno electron microscopy. FEBS Lett 580: 2006-2010, 2006.

61. Chaban YL, Juliano S, Boekema EJ and Gruber G: Interaction between subunit $\mathrm{C}$ (Vma5p) of the yeast vacuolar ATPase and the stalk of the C-depleted V(1) ATPase from Manduca sexta midgut. Biochim Biophys Acta 1708: 196-200, 2005.

62. Drory O, Frolow F and Nelson N: Crystal structure of yeast $\mathrm{V}$-ATPase subunit $\mathrm{C}$ reveals its stator function. EMBO Rep 5: $1148-1152,2004$.

63. Inoue $\mathrm{T}$ and Forgac $\mathrm{M}$ : Cysteine-mediated cross-linking indicates that subunit $\mathrm{C}$ of the $\mathrm{V}$-ATPase is in close proximity to subunits $\mathrm{E}$ and $\mathrm{G}$ of the $\mathrm{V} 1$ domain and subunit a of the V0 domain. J Biol Chem 280: 27896-27903, 2005.

64. Forgac M: Vacuolar ATPases: rotary proton pumps in physiology and pathophysiology. Nat Rev Mol Cell Biol 8: 917-929, 2007.

65. Peng S, Stone D and Xie X: Reconstitution of recombinant 40-kDa subunit of the clathrin-coated vesicle H(+)-ATPase. J Biol Chem 268: 23519-23523, 1993.

66. Gruber G: Structural features and nucleotide-binding capability of the $\mathrm{C}$ subunit are integral to the regulation of the eukaryotic V1Vo ATPases. Biochem Soc Trans 33: 883-885, 2005.

67. Armbruster A, Hohn C, Hermesdorf A, Schumacher K, Borsch M and Gruber G: Evidence for major structural changes in subunit $\mathrm{C}$ of the vacuolar ATPase due to nucleotide binding. FEBS Lett 579: 1961-1967, 2005

68. Puopolo K, Sczekan M, Magner R and Forgac M: The 40-kDa subunit enhances but is not required for activity of the coated vesicle proton pump. J Biol Chem 267: 5171-5176, 1992.

69. Beltran C, Kopecky J, Pan YC, Nelson H and Nelson N: Cloning and mutational analysis of the gene encoding subunit $\mathrm{C}$ of yeast vacuolar H(+)-ATPase. J Biol Chem 267: 774-779, 1992. 
70. Voss M, Vitavska O, Walz B, Wieczorek $\mathrm{H}$ and Baumann O: Stimulus-induced phosphorylation of vacuolar H(+)-ATPase by protein kinase A. J Biol Chem 282: 33735-33742, 2007.

71. Smardon AM and Kane PM: RAVE is essential for the efficient assembly of the $\mathrm{C}$ subunit with the vacuolar $\mathrm{H}(+)$-ATPase. J Biol Chem 282: 26185-26194, 2007

72. Keenan Curtis K and Kane PM: Novel vacuolar $\mathrm{H}^{+}$-ATPase complexes resulting from overproduction of Vma5p and Vma13p. J Biol Chem 277: 2716-2724, 2002.

73. Ma L and Center MS: The gene encoding vacuolar $\mathrm{H}(+)$-ATPase subunit $\mathrm{C}$ is overexpressed in multidrug-resistant HL60 cells. Biochem Biophys Res Commun 182: 675-681, 1992.
74. Murakami T, Shibuya I, Ise T, Chen ZS, Akiyama S and Nakagawa M: Elevated expression of vacuolar proton pump genes and cellular PH in cisplatin resistance. Int J Cancer 93: 869-874, 2001

75. Bowman BJ and Bowman EJ: Mutations in subunit $\mathrm{C}$ of the vacuolar ATPase confer resistance to bafilomycin and identify a conserved antibiotic binding site. J Biol Chem 6: 3965-3972, 2002.

76. Martinez Muñoz GA and Kane P: Vacuolar and plasma membrane proton pumps collaborate to achieve cytosolic $\mathrm{pH}$ homeostasis in yeast. J Biol Chem 29: 20309-20319, 2008. 